\title{
GCU
}

Glasgow Caledonian

University

University for the Common Good

\section{Evolutions of SIFs of concrete under sustained loading by considering the effects of stress relaxations}

Dong, Wei; Li, Jie; Zhang, Xue; Zhang, Binsheng

Published in:

Journal of Materials in Civil Engineering

DOI:

10.1061/(ASCE)MT.1943-5533.0002949

Publication date:

2019

Document Version

Author accepted manuscript

Link to publication in ResearchOnline

Citation for published version (Harvard):

Dong, W, Li, J, Zhang, X \& Zhang, B 2019, 'Evolutions of SIFs of concrete under sustained loading by considering the effects of stress relaxations', Journal of Materials in Civil Engineering, vol. 31, no. 12. https://doi.org/10.1061/(ASCE)MT.1943-5533.0002949

\section{General rights}

Copyright and moral rights for the publications made accessible in the public portal are retained by the authors and/or other copyright owners and it is a condition of accessing publications that users recognise and abide by the legal requirements associated with these rights.

Take down policy

If you believe that this document breaches copyright please view our takedown policy at https://edshare.gcu.ac.uk/id/eprint/5179 for details

of how to contact us. 
$5{ }^{1}$ Professor, State Key Laboratory of Coastal and Offshore Engineering, Dalian University of 6 Technology, Dalian 116024, P. R. China.

7 *Corresponding author, E-mail: dongwei@dlut.edu.cn

$9 \quad{ }^{2}$ Doctoral student, State Key Laboratory of Coastal and Offshore Engineering, Dalian University of 10 Technology, Dalian 116024, P. R. China. E-mail: ngdlj2013@163.com

$12{ }^{3}$ Associate Professor, State Key Laboratory of Coastal and Offshore Engineering, Dalian University of 13 Technology, Dalian 116024, P. R. China. E-mail: Xuezhang@dlut.edu.cn

$15{ }^{4}$ Professor, Department of Civil Engineering and Environmental Management, School of Computing, 16 Engineering and Built Environment, Glasgow Caledonian University, Glasgow G4 0BA, Scotland, 17 United Kingdom. E-mail: Ben.Zhang@gcu.ac.uk 


\section{Abstract}

26 Sustained loading has an important impact on concrete structures in service due to deteriorations of 27 material properties and degradations of durability. Sustained loading and three-point bending (TPB) 28 tests were carried out to study the influence of long-term loading on the fracture of concrete. The 29 specimens were firstly tested under three load levels, i.e. $30 \%$ and $60 \%$ of the maximum load and the 30 crack initiation load over 30 days. After that, these specimens were removed from the loading frames 31 and immediately loaded up to failure under static TPB loading. The critical crack propagation length $32\left(\Delta a_{\mathrm{c}}\right)$, the initial cracking load $\left(P_{\text {ini }}\right)$, the peak load $\left(P_{\max }\right)$ and the fracture energy $\left(G_{\mathrm{f}}\right)$ were obtained 33 in the TPB tests. Accordingly, the initial fracture toughness $\left(K_{\mathrm{IC}}^{\mathrm{ini}}\right)$ and the unstable fracture toughness $34\left(K_{\mathrm{IC}}^{\mathrm{un}}\right)$ were determined by considering the stress relaxation at the pre-crack tip. Furthermore, the 35 fracture properties of concrete affected by the long-term loading can be obtained by comparing with 36 those from the static TPB tests. The results indicated that the stress relaxation at the pre-crack tip 37 caused by the viscoelasticity of concrete led to the increases in $P_{\text {ini }}$ and $P_{\max }$, but had almost no 38 effects on $\Delta a_{\mathrm{c}}$ and $G_{\mathrm{f}}$. The formulae for calculating $K_{\mathrm{IC}}^{\mathrm{ini}}$ and $K_{\mathrm{IC}}^{\mathrm{un}}$ from linear elastic fracture mechanics would no longer be appropriate for those creep specimens and would overestimate the 40 values of $K_{\mathrm{IC}}^{\mathrm{ini}}$ and $K_{\mathrm{IC}}^{\mathrm{un}}$. By taking into account the stress relaxation, the calculated values of $K_{\mathrm{IC}}^{\mathrm{ini}}$ and $K$

41 un for the creep specimens were almost the same as those under the static loading. Therefore, the values 42 of $K_{\mathrm{IC}}^{\mathrm{ini}}$ and $K_{\mathrm{IC}}^{\mathrm{un}}$ derived from the static TPB tests can still be used to evaluate the cracking-resistance of 43 concrete materials and the stability of concrete structures under different load levels.

44 Keywords: Concrete; Fracture properties; SIF; Sustained loading; Stress relaxation.

\section{Introduction}

Special concrete structures, such as nuclear reactor containments, cooling towers and gravity

48 dams, are usually subjected to long-term external loading during their service life, where the 49 deformations and stress levels in the structures will change over time, which may induce the decrease 
50 of the load-carrying capacity and weaken the integrity and stability. Therefore, it is significant to have

51 a deep understanding of the impact of long-term loading on the mechanical and fracture properties of

52 concrete, so that safe operations of the structures can be comprehensively assessed and ensured. In the

53 analyses on the fracture behaviors of concrete structures under long-term loading, the loading level

54 together with the load duration have an important impact on the initiation and propagation of internal

55 cracks. In common practice, low loading levels cause linear creep deformations and the resulting instantaneous viscoelastic characteristics of concrete remain linear. Under high loading levels, on the

57 contrary, internal cracks propagate and interact with viscoelasticity, leading to nonlinear responses of concrete structures and even triggering the failure of the whole structures. In past decades, many

59 investigations have focused on the time-dependent fracture of concrete in academic and engineering 60 fields (Bažant and Li 1996; Barpi et al. 1999; Valente and Barpi 2011).

Under high sustained loading levels, the creep can usually be divided into three stages (Zhou 1992; Bažant and Xian 1997). In the primary stage, the creep rate is high and gradually decreases to form a plateau over the time. After that, the creep rate keeps constant in the following creep stage. Along with the damage evolution, creep process enters into the tertiary stage and leads to the final structure failure. Zhou (1992) studied the time-dependent fracture of concrete under different high loading levels, i.e. $P / P_{\max }=0.92,0.85,0.80$ and 0.76 , and his results showed that the concrete specimens failed under high load levels in the long-term loading tests, while the fracture energy was almost not affected by the sustained load conditions. Bažant and Xian (1997) investigated the growth of cracks in the concrete under various high sustained loading levels, and their results showed that the load levels had a significant impact on the service life of concrete structures, which decreased with the increase of the loading levels. They also confirmed the time-dependent fracture was not caused by the

72 viscoelastic characteristics of concrete, but due to that time-dependent crack growth, which would

73 dominate the crack opening displacement in the final creep stage. Saliba et al. (2014) observed similar

74 phenomena by using the acoustic emission technique to analyze the damage evolution under sustained 
75 loading. Bažant and Gettu (1992) experimentally studied the influence of loading rate on the fracture

76 behavior of concrete structures, and their results showed that there was a strong correlation between

77 the crack growth and the viscoelastic characteristics of the materials, which resulted in the decrease in

78 the fracture toughness, fracture energy and residual load-carrying capacity of concrete at a slower

79 loading rate. Their experimental results can be explained by using the relaxation of the cohesive stress

80 and energy barrier in the fracture process zone (FPZ) during the crack propagation. Based on the

81 extensive experimental studies and theoretical analyses, several time-dependent models have been

82 proposed to investigate the nonlinear creep in concrete. For examples, the model based on the

83 activation theory for bond ruptures by Li and Bažant (1997) and the damage mechanics model coupled

84 with linear viscoelasticity by Mazzotti and Savoia (2003) have been widely used for simulating the

85 time-dependent fracture of concrete. Meanwhile, considering most of concrete structures, in practical

86 engineering, do not fail but maintain equilibrium and integrity under long-term loading, the fracture

87 properties of concrete after sustained loading need to be further explored.

Under low sustained loading levels, no crack propagations will happen so that the linear

89 viscoelastic characteristics of concrete govern the deformations and stress distributions in concrete

90 structures. Saliba et al. $(2010 ; 2012)$ investigated the fracture behavior of concrete by conducting

91 three-point bending (TPB) tests on the specimens after long-term loading tests, and found that the

92 sustained loading led to a consolidated effect in the compressive zone of the concrete beam, which

93 accordingly would increase the fracture energy, fracture toughness and residual load capacity of the

94 concrete specimens. In contrast, Omar et al. (2009) obtained the reverse conclusion under the same

95 experimental conditions by indicating that the low sustained loading levels had little impact on the

96 residual capacity and the fracture energy decreased compared with the results from the static tests. The

97 investigations carried out by Dong et al. (2018a; 2018b) and Rong et al. (2019) mainly focused on

98 the influence of long-term loading on tension-softening constitutive and fracture process zone as well

99 as the size effect on fracture properties of concrete after sustained loading. Compared with the static 
100 loading condition, a smaller free-stress crack opening displacement would be achieved after 101 long-term loading, and the full FPZ length would decrease accordingly. Meanwhile, the obvious size 102 effects on the fracture properties of concrete after sustained loading were observed.

103 Creep and relaxation are different characteristics of one identical physical phenomenon for 104 viscoelastic material like concrete (Oza et al. 2003). Stress relaxation is accompanied by the 105 occurrence of creep and will lead to stress re-distributions in concrete elements. According to the 106 researchers, the initial stress would be released with a considerable portion due to the occurrence of 107 stress relaxation (Oza et al. 2003; Beushausen et al. 2012; Hamed 2016), so that the influence of the 108 stress relaxation on the fracture properties of concrete after long-term load should not be neglected. 109 For the pre-notched three-point bending beams under low sustained load, there is a significant stress 110 concentration existing at the tip of pre-notched (Bažant and Gett 1992). Due to the occurrence of stress 111 relaxation, stress concentration will be reduced, resulting in the decrease of stress intensity factor (SIF). 112 As a result, the linear elastic fracture mechanics (LEFM) cannot be employed to calculate the fracture 113 parameters of concrete without considering the effect of the material viscoelasticity. Therefore, it is 114 significant to develop a calculation method to derive the SIF under low sustained load, so that the 115 effect of the viscoelasticity in concrete on the fracture properties can be assessed more compressively. 116 The initial and unstable fracture toughness, i.e. $K_{\mathrm{IC}}^{\mathrm{ini}}$, and $K_{\mathrm{IC}}^{\mathrm{un}}$ in double- $K$ theory have been 117 applied to determine the crack initiation and unstable propagation of concrete structures (Xu and 118 Reinhardt 1999a, b, c). Many studies have been conducted to investigate the influence of concrete 119 strength (Xu and Zhu 2009), aggregate size (Zhang et al. 2010), specimen boundary (Xu and 120 Reinhardt 1999c; Kumar and Barai 2009) and specimen size (Kumar and Barai 2008; Zhang and Xu 121 2011) on these two toughnesses. The results indicated that $K_{\mathrm{IC}}^{\mathrm{ini}}$, and $K_{\mathrm{IC}}^{\mathrm{un}}$ can be regarded as the 122 material parameters in the assessment of anti-cracking and stability of concrete structures. There is a 123 RILEM recommendation on the testing methods to obtain the double- $K$ parameters (RILEM 1990). In 124 addition, the initial fracture toughness was also introduced in the crack propagation criterion to 
125 determine the crack evolution and calculate the crack resistance (Dong et al. 2013a, b). However, it 126 should be noted that all studies on the double- $K$ parameters were conducted under a static load 127 condition. To the best of author's knowledge, there is no report on the effect of long term load on 128 double- $K$ fracture parameters. For concrete under long-term loading, the fracture properties of the 129 concrete cannot be reflected by those obtained from static loading due to the viscoelastic properties 130 of concrete. Therefore, from the point of view of practical application, it is more significant to study 131 the variation of the double- $K$ parameters under sustained load, so that the anti-cracking and fracture 132 stability of the structures can be assessed more objectively.

133 The main purpose of this paper is to study the influence of long-term load on double-fracture 134 parameters of concrete under TPB load. Firstly, the creep tests on concrete TPB specimens were tested 135 with three load levels, i.e., $30 \% P_{\max }, 60 \% P_{\max }$ and crack initiation load. After the creep test, the TPB 136 fracture test were carried out, and the initial cracking and peak load, critical crack propagation length 137 were tested. Through considering the stress relaxation at the tip of crack, the initial and unstable 138 fracture toughnesses were calculated numerically. Hence, the impacts of sustained loading on the 139 double- $K$ parameters were discussed.

\section{Experimental Programs}

\section{Specimen preparations}

The dimensions of the concrete specimens adopted in this study were $500 \mathrm{~mm} \times 100 \mathrm{~mm} \times 100$ $\mathrm{mm}$ ( length $\times$ width $\times$ depth ) with a pre-notch of $30 \mathrm{~mm}$. Portland cement with the strength grade of 42.5 $\mathrm{MPa}$, coarse aggregate with the maximum size of $10 \mathrm{~mm}$ and river sand with the maximum size of $5 \mathrm{~mm}$ were used for making the specimens. The mix proportions were cement : water : sand : aggregate $=1: 0.60: 2.01: 3.74$ by weight. One day after casting, the specimens were demolded and

147 then kept in the curing room with $20 \pm 2{ }^{\circ} \mathrm{C}$ and $90 \%$ relative humidity (RH) over 28 days. After 148 that, the concrete prism specimens of $300 \mathrm{~mm} \times 150 \mathrm{~mm} \times 150 \mathrm{~mm}$ were used to determine the elastic modulus, and the $150 \mathrm{~mm}$ cube specimens were used to determine the compressive strength and the 
150 splitting tensile strength. The test methods were recommended by GB/T50081 Standard for Test

151 Method of Mechanical Propertied on Ordinary Concrete (NSPRC 2003). The elastic modulus $(E)$,

152 compressive strength $\left(f_{\mathrm{c}}\right)$ and splitting tensile strength $\left(f_{\mathrm{t}}\right)$ measured at the age of 28 days are listed in 153 Table 1.

\section{Creep tests}

155 To calibrate the applied load in the sustained loading tests, three specimens were tested under the 156 standard TPB loading to obtain the peak load $P_{\max }$ with a mean value of $4.05 \mathrm{kN}$. The creep 157 specimens were loaded in frames which were specifically designed for the creep tests, as shown in 158 Fig. 1. The load was applied to the specimen by turning the bolt. To ensure that the applied load 159 accurately reached to the specified load, a load cell was connected onto the bolt and the data 160 collection system with digital display was used to record the load instantaneously. The sustained 161 loading tests were carried out in a room with $20 \pm 2{ }^{\circ} \mathrm{C}$ and $50 \% \mathrm{RH}$. Double-layer aluminium paper 162 was pasted to the specimens to prevent the loss of moisture.

To study the time-dependent response of concrete under different load levels, $30 \% P_{\max }(30 \% \times$ $4.05=1.22 \mathrm{kN}), 60 \% P_{\max }(60 \% \times 4.05=2.43 \mathrm{kN})$ and the crack initiation load were utilized in the sustained loading tests. Three specimens were adopted for each loading level. To obtain the crack initiation load, four strain gages were symmetrically attached at a distance of $5 \mathrm{~mm}$ to the tip of 167 pre-notch on both sides of each specimen. The readings of the strain gages increased with the 168 increase of the applied load under the static TPB loading. Once a new crack formed, the readings of 169 the strain gages would decrease because of the release of the strain energy stored around the crack tip 170 (Dong et al. 2013a). Thus, the crack initiation loads for the three creep specimens were determined as $1712.70 \mathrm{kN}, 2.75 \mathrm{kN}$ and $2.79 \mathrm{kN}$, respectively. It should be noted that the applied loads decreased with

172 the increase of loading time due to the development of deformation during the sustained loading tests, 173 which led to the applied loads less than the specified load. Once the applied loads dropped by $2 \%$, 174 they were immediately adjusted back to the specified load level. The dial gages were used to measure 
175 the loading point displacement $(\delta)$ and the crack mouth opening displacement $(C M O D)$. Together with

176 the creep specimens, three specimens were made and kept under the same conditions, which were

177 served as reference specimens, named as the "aging specimens".

178 TPB tests

179 After the 30-day load duration, the creep specimens were removed from the frames and 180 immediately loaded up to failure under the TPB loading. The TPB tests were conducted in a $250 \mathrm{kN}$ 181 closed loop servo-controlled testing machine under a displacement controlled mode at a loading rate 182 of $0.024 \mathrm{~mm} / \mathrm{min}$. Besides, the $C M O D$ and the loading point displacement were measured by using 183 the clip gauges, see Fig. 2(a). Meanwhile, four clip gauges were distributed on one side of the 184 specimen to track the propagation of crack, see Fig. 2(b).

\section{Numerical Analyses}

186 Creep and relaxation are two different characteristics of one identical physical phenomenon for 187 viscoelastic material like concrete, which indicates that stress relaxation is accompanied by the 188 occurrence of creep. The stress relaxation usually occurs in the primary and secondary creep stages 189 (Yuan et al. 2013). Therefore, in this study, the stress relaxation was not considered when the load 190 increased from zero to the specified value, and it would be calculated at the beginning of the primary 191 creep stage. The creep model based on the stress power function proposed by Norton (Kraus and 192 Harry 1980) was employed to assess the effect of the stress relaxation at the crack tip in this study as

$$
\&=A \sigma^{\mathrm{n}}
$$

194 where $A$ is the empirical constant, $\sigma$ is the initial stress, and $n$ is the exponential index for the stress $\sigma$.

The whole creep deformation of concrete occurred in the stable creep stage so that the model by 197 Norton was appropriate to apply because it can reflect the variations of the strain under sustained 
198 loading. In addition, for the concrete under sustained loading, the creep deformation can also be 199 calculated from

$$
\&=-\frac{1}{E} \frac{d \sigma}{d t}
$$

where $t$ is the loading time. By substituting Eq. (2) into Eq. (1) and making integration over time, the stress variation over time can be obtained as (Naoki et al. 2011).

$$
t=\frac{1}{A E(n-1)}\left(\frac{1}{\sigma^{\mathrm{n}-1}}-\frac{1}{\sigma_{0}^{\mathrm{n}-1}}\right)
$$

204 where $\sigma_{0}$ is the initial stress at the time $t=0$. obtained in the sustained loading tests. It should be noted that the stress at the front of the pre-crack decreased with the increase of the distance to the pre-crack tip under constant sustained loading. The experimental results by Hamed (2016) indicated that a higher initial stress led to a larger stress relaxation. Fig. 3 illustrates the stress variations in front of the pre-crack tip with respect to different TPB loading times.

To verify the proposed model, finite element analyses for the TPB specimens were conducted.

213 The concrete was considered as an isotropic material and the adopted mechanical properties were 214 based on the experimental results, i.e. the tensile strength, elastic modulus and Poisson's ratio were 215 taken as $3.07 \mathrm{MPa}, 39.1 \mathrm{GPa}$ and 0.2 , respectively. The element of Plane 182 provided by ANSYS FE 216 code was used in the numerical simulations, which is a 2-D 4-node element with quadratic 217 displacement behavior. It could also support the analyses of plasticity, creep, stress stiffening, large 218 deflection and large strain. The triangular mesh was adopted in the numerical simulation. Meanwhile, 219 considering the stress singularity on the crack tip, the region around the crack tip was set as singular 220 element to calculate the SIF at the tip of crack. Therefore, a circle was set about the tip of the crack, 221 where the crack tip is the center of the circle with a radius of $2 \mathrm{~mm}$. The first row of elements around 
222

223

the crack tip had a radius of $1 / 2 \mathrm{~mm}$, and their mid-side nodes were placed at the quarter points, i.e. with a radius of $1 / 8 \mathrm{~mm}$. The detail of the numerical mesh is shown in Fig. 4. In numerical analyses, a static analysis would be conducted first through applying the load to the specified value. Thereafter, a time-history analysis would be performed where the loading duration would be controlled as 30 days corresponding to the case in the creep tests. During the process of the time-history analysis, the deformations and stresses at different nodes would either increase or decrease over time, which can be determined based on Eqs. (2) and (3).

According to the research by Beushausen et al. (2012), the magnitudes of the ultimate relaxation in front of the pre-crack tip were approximately $20-45 \%$ of the initial stress, as shown in Fig. 5(a) where $\sigma_{\mathrm{t}}$ is the stress corresponding to the varying time $t$. By combining with the tested $\delta$ - $t$ curves in this study and applying Eq. (3) to simulate the deformations of the specimens, the values of $A$ and $n$ were determined as $1.2 \times 10^{-7}$ and 4 , respectively. Accordingly, the range of the stress relaxation for different distances from the pre-crack tip approximately ranged between $20 \%$ and $45 \%$ of the initial stress. The comparisons of the $\delta-t$ curves between the numerical and experimental results for various loading levels are shown in Figs. 5(b) to (d), where the grey bands indicate the scattered results represented by three experimental curves for each case, and a good agreement between them can be observed. Here, C-30, C-60 and C-ini refer to the specimens subjected to $30 \% P_{\max }, 60 \% P_{\max }$ and the crack initiation load, respectively. It can be seen that the displacement increased rapidly under the instantaneous loading (primary creep) and stabilized after a few days (secondary creep). Similar results were also observed by Omar et al. (2009) and Saliba et al. (2010; 2014) in their experiments. In summary, the obtained values of $A=1.2 \times 10^{-7}$ and $n=4$ in Eq. (3) can well reflect the viscoelastic characteristics of the concrete used in this study, so they can be employed to calculate the fracture parameters for the specimens under sustained loading.

The $J$-integral method was employed to calculate the SIF by means of the ANSYS FE code. The $J$-integral can be expressed as 


$$
J=\int_{\Gamma}\left[\left(w-\sigma_{\mathrm{xx}} \frac{\partial u}{\partial x}-\tau_{\mathrm{xy}} \frac{\partial v}{\partial x}\right) \mathrm{d} y+\left(\tau_{\mathrm{xy}} \frac{\partial u}{\partial x}+\sigma_{\mathrm{yy}} \frac{\partial v}{\partial x}\right) \mathrm{d} x\right]
$$

248 where $w$ is the strain energy density, $\sigma_{\mathrm{xx}}, \sigma_{\mathrm{yy}}$ and $\tau_{\mathrm{xy}}$ are the stress components, $u$ and $v$ are the

249 displacement components on the integral path, and $\Gamma$ is the path for the integration. Thus, the 250 relationship between the $J$-integral, $J$, and the SIF, $K$, can be written as

$$
J=\frac{K^{2}}{E}
$$

252 By combining Norton's model and the $J$-integral method, the SIFs at various creep stages can be 253 calculated accordingly.

\section{Results and Discussion}

As indicated above, after the 30-day load duration, the creep specimens were removed from the

256 frames and immediately loaded up to failure under the TPB loading. The experimental results are 257 listed in Table 2 where C-aging denotes the reference specimens, $P_{\text {ini }}$ and $P_{\max }$ denote the initial 258 cracking and peak loads, $K_{\mathrm{IC}}^{\mathrm{ini}}$ and $K_{\mathrm{IC}}^{\mathrm{un}}$ denote the initial fracture toughness and unstable fracture 259 toughness, $K_{\mathrm{IC}}^{\sigma}$ denotes the SIF caused by the cohesive stress at the critical state, and $G_{\mathrm{f}}, C M O D_{\mathrm{c}}$ and $260 a_{\mathrm{c}}$ denote the fracture energy, critical crack mouth opening displacement and critical crack length, 261 respectively. It can be seen that the fracture energy was little affected by sustained loading. However, 262 compared with the $\mathrm{C}$-aging series specimens, the mean values of $P_{\text {ini }}$ for the $\mathrm{C}-30, \mathrm{C}-60$ and $\mathrm{C}$-ini 263 series specimens increased by $19.0 \%, 23.3 \%$ and $23.6 \%$, while the mean values of $P_{\max }$ for the C-30, 264 C-60 and C-ini series specimens increased by 10.8\%, 14.0\% and 16.5\%, respectively. Both $P_{\text {ini }}$ and $265 P_{\max }$ exhibited the increasing trends with the increased sustained load levels.

\section{Effects of stress relaxation on the initial fracture toughness}

After obtaining the initial cracking load from the experimental results, the initial fracture toughness $K_{\mathrm{IC}}^{\mathrm{ini}}$ can be calculated from (Xu and Reinhardt 1999b)

$$
K=\frac{3 P S}{B D^{2}} \sqrt{a} F\left(\frac{a}{D}\right)
$$


271 depth, $a$ is the crack length, and $F\left(\frac{a}{D}\right)$ can be calculated from

$$
F\left(\frac{a}{D}\right)=\frac{1.99-\frac{a}{D}\left(1-\frac{a}{D}\right)\left[2.15-3.93 \frac{a}{D}+2.7\left(\frac{a}{D}\right)^{2}\right]}{\left(1+2 \frac{a}{D}\right)\left(1-\frac{a}{D}\right)^{3 / 2}}
$$

273 Table 2 lists the values of $K_{\mathrm{IC}}^{\mathrm{ini}}$ obtained from Eq. (6). It can be seen that $K_{\mathrm{IC}}^{\mathrm{ini}}$ increased significantly for 274 all creep specimens compared with the C-aging series specimens. The mean values of $K_{\mathrm{IC}}^{\text {ini }}$ for the 275 C-aging, C-30, C-60 and C-ini series specimens were $0.52 \mathrm{MPa} \cdot \mathrm{m}^{1 / 2}, 0.63 \mathrm{MPa} \cdot \mathrm{m}^{1 / 2}, 0.68 \mathrm{MPa} \cdot \mathrm{m}^{1 / 2}$ 276 and $0.69 \mathrm{MPa} \cdot \mathrm{m}^{1 / 2}$, respectively. Obviously, the increase in $K_{\mathrm{IC}}^{\mathrm{ini}}$ for the creep specimens was caused 277 by the increase of the initial cracking load $P_{\text {ini }}$ if the stress relaxation was not considered in the 278 analyses.

In the numerical analysis, three load levels, i.e. $1.22 \mathrm{kN}, 2.43 \mathrm{kN}$ and $2.75 \mathrm{kN}$, were applied onto the C-30, C-60 and C-ini series specimens, respectively. Fig. 6 illustrates the stress evolution over time at different nodes in front of the pre-crack tip obtained from the numerical analyses, where the distances of Nodes 1, 2 and 3 to the pre-crack tip were $0.131 \mathrm{~mm}, 0.240 \mathrm{~mm}$ and $0.325 \mathrm{~mm}$, respectively. It can be seen that the stresses decreased rapidly over time and tended to be stable after 10 days. Taking the $\mathrm{C}$-ini specimen as an example, after loading over 30 days, the final stresses at Nodes 1,2 and 3 dropped to $45 \%, 51 \%$ and $54 \%$ of their initial values.

In the following static TPB tests, the mean initial cracking loads obtained from the experimental results with respect to the $\mathrm{C}$-aging, $\mathrm{C} 30, \mathrm{C} 60$ and $\mathrm{C}$-ini series specimens were $2.75 \mathrm{kN}, 3.28 \mathrm{kN}, 3.39$ $\mathrm{kN}$ and $3.40 \mathrm{kN}$, respectively. The loading history in the tests can be summed up as follows. In the sustained loading tests, the load was hold as $P_{0}$ for 30 days and then unloaded to zero, while in the TPB tests, the load was reloaded to $P_{0}$ and increased successively to the initial cracking load $P_{\text {ini }}$ and 291 the peak load $P_{\max }$, respectively. 
Accordingly, the variations of the SIFs for the specimens in the sustained loading tests were assessed using $J$-integral method, as shown in Fig. 7. It can be seen that the SIFs decreased rapidly in 294 the first day and became fully stabilized after a few weeks. For the C-30, C-60 and C-ini series 295 specimens, the SIFs at the end of the creep tests decreased from their initial values by $62 \%, 57 \%$ and $29658 \%$, respectively.

Fig. 8 illustrates the complete evolution process of the SIF in the creep and TPB tests. In the creep tests with a sustained load $P_{0}$, the SIF decreased rapidly from $K_{0}$ (Point A in Fig. 8) in the first day and became fully stabilized after a few weeks until $K_{1}$ was reached (Point B in Fig. 8) at the end of the creep tests. In the following TPB tests, the load increased from 0 to $P_{0}$, i.e. the applied sustained load in creep tests. At that moment, the SIF corresponding to $P_{0}$ would be $K_{2}$ (Point C in Fig. 8), which had an increment of $\Delta K_{1}$ from $K_{1}$ but was less than $K_{0}$ due to the effect of the residual stress relaxation in the creep tests. Thereafter, the load increased to the initial cracking load $P_{\text {ini }}$ and the initial fracture toughness $K_{\mathrm{IC}}^{\mathrm{ini}}$ could be obtained (Point D in Fig. 8). Finally, the peak load $P_{\max }$ was reached and the unstable fracture toughness $K_{\mathrm{IC}}^{\text {un }}$ would be obtained (Point E in Fig. 8). It should be noted that the values of $K_{\mathrm{IC}}^{\mathrm{ini}}$ and $K_{\mathrm{IC}}^{\mathrm{un}}$, both considering the effects of the stress relaxation, were different from those calculated using Eq. (6) based on the LEFM theory.

Figs. 9(a) to (c) illustrate the evolution processes of the SIFs for the C-30, C-60 and C-ini series specimens obtained from the numerical analyses. In these figures, Points A to D corresponded to those in Fig. 8. Taking the C-60 series specimens as examples, the SIF caused by the load of $2.43 \mathrm{kN}$ at the beginning of the creep tests was $0.43 \mathrm{MPa} \cdot \mathrm{m}^{1 / 2}$ (Point A in Fig. 9(b)) and decreased by 0.24 $\mathrm{MPa} \cdot \mathrm{m}^{1 / 2}$ after 30 days (Point B in Fig. 9(b)). In the TPB tests, the SIF was $0.39 \mathrm{MPa} \cdot \mathrm{m}^{1 / 2}$ caused by 313 the load of $2.43 \mathrm{kN}$ (Point C in Fig. 9(b)), i.e. the load applied in the creep tests. This value was less 314 than the threshold value of $0.43 \mathrm{MPa} \cdot \mathrm{m}^{1 / 2}$ from the LEFM theory due to the effect of the stress 315 relaxation. Thereafter, the crack initiated when the load reached $3.40 \mathrm{kN}$ and the initial fracture 316 toughness was calculated as $0.53 \mathrm{MPa} \cdot \mathrm{m}^{1 / 2}$, which was slightly different from the calculated value of 
$3170.68 \mathrm{MPa} \cdot \mathrm{m}^{1 / 2}$ from Eq. (6). Accordingly, the initial fracture toughnesses calculated using these two 318 methods for all specimens are also listed in Table 2.

319 In summary, based on the numerical results and considering the stress relaxation in the sustained 320 loading tests, the mean values of $K_{\mathrm{IC}}^{\mathrm{ini}}$ for the C-aging, C-30, C-60, and C-ini series specimens were 321 determined as $0.50 \mathrm{MPa} \cdot \mathrm{m}^{1 / 2}, 0.53 \mathrm{MPa} \cdot \mathrm{m}^{1 / 2}, 0.53 \mathrm{MPa} \cdot \mathrm{m}^{1 / 2}$ and $0.54 \mathrm{MPa} \cdot \mathrm{m}^{1 / 2}$, which corresponded 322 to the mean values of the initial cracking loads of $2.75 \mathrm{kN}, 3.28 \mathrm{kN}, 3.39 \mathrm{kN}$ and $3.40 \mathrm{kN}$, respectively.

323 In contrast, based on the LEFM theory, the corresponding values were $0.52 \mathrm{MPa} \cdot \mathrm{m}^{1 / 2}, 0.63 \mathrm{MPa} \cdot \mathrm{m}^{1 / 2}$, $3240.68 \mathrm{MPa} \cdot \mathrm{m}^{1 / 2}$ and $0.69 \mathrm{MPa} \cdot \mathrm{m}^{1 / 2}$. It can be confirmed that for the creep specimens, the initial 325 fracture toughness would be overestimated if the influence of stress relaxation at the pre-crack tip 326 would not be considered and only the LEFM theory would be adopted. In fact, the actual $K_{\mathrm{IC}}^{\mathrm{ini}}$ is not 327 affected by long-term loading and can still be regarded as the material parameter to determine the 328 crack initiation in the fracture analyses on the concrete under long-term loading.

\section{Effects of stress relaxation on the critical crack length}

The critical crack length $a_{\mathrm{c}}$, i.e. the crack length corresponding to the maximum load, is a significant parameter for assessing the critical crack propagation of concrete. To study the impact of 332 long-term loading on this parameter, the $C M O D$ and four crack opening displacements $(C O D s)$ along 333 the ligament were measured using clip gages in the static TPB tests, as shown in Fig. 2(b). It can be 334 seen from Fig. 10 that the relationship between the values of the $C M O D$ and the four $C O D$ s is 335 approximately linear. In addition, according to the experimental results, the mean value of crack tip 336 opening displacement $(C T O D)$ corresponding to the initial cracking load, $w_{\text {ini, }}$, of the aging specimens 337 was $8.423 \mu \mathrm{m}$, which can be used to determine the crack tip. Based on the relationship and $w_{\text {ini, }}$, the 338 critical crack length can be determined. Accordingly, the influence of long-term loading on the 339 critical crack length can be obtained by comparing with those from the aging specimens. 


$$
C M O D_{\mathrm{c}}=\frac{24 P_{\max } a_{\mathrm{c}}}{B D E} V\left(\frac{a_{\mathrm{c}}}{D}\right)
$$

343 For $S / D=4$, the function $V\left(\frac{a_{\mathrm{c}}}{D}\right)$ is given as follow

$$
V\left(\frac{a_{\mathrm{c}}}{D}\right)=0.76-2.28\left(\frac{a_{\mathrm{c}}}{D}\right)+3.87\left(\frac{a_{\mathrm{c}}}{D}\right)^{2}-2.04\left(\frac{a_{\mathrm{c}}}{D}\right)^{3}+0.66\left(1-\frac{a_{\mathrm{c}}}{D}\right)^{-2}
$$

345 where $C M O D_{\mathrm{c}}$ is the crack mouth opening displacement corresponding to the peak load.

346 It can be seen from Table 2 that the values of $a_{\mathrm{c}}$ for the $\mathrm{C}$-aging series specimens determined from the 347 tests and Eq. (8) are very close, which validates the test method by using the clip gauges to determine

$348 a_{\mathrm{c}}$ in this study. In addition, the values of $a_{\mathrm{c}}$ for the three series creep specimens, i.e. C-30, C-60 and 349 C-ini series specimens, are close to those from the C-aging series specimens. Though the stress 350 relaxation for the creep specimens led to the increase in $P_{\max }$, the increased $P_{\max }$ had little effect on $a_{\mathrm{c}}$ 351 and Eq. (8) from the modified LEFM can still be utilized to calculate the critical crack length.

\section{Effect of stress relaxation on the unstable fracture toughness}

The unstable fracture toughness $K_{\mathrm{IC}}^{\mathrm{un}}$ can be determined by substituting $P_{\max }$ and $a_{\mathrm{c}}$ into Eq. (6).

Table 2 lists the calculated values of $K_{\mathrm{IC}}^{\mathrm{un}}$ by utilizing Eq. (6), which indicate that the unstable fracture toughness increased with the increasing sustained loading. It should be noted that for the creep specimens, the calculated $K_{\mathrm{IC}}^{\mathrm{ini}}$ from Eq. (6) could be overestimated because the effect of the stress relaxation was not considered. Hence, the calculated $K_{\mathrm{IC}}^{\mathrm{un}}$ could also be overestimated if Eq. (6) was adopted.

The scenario would be different if the stress relaxation was considered in the fracture analyses. According to the research by Xu and Reinhardt (1999b), the relationship between $K_{\mathrm{IC}}^{\mathrm{ini}}$ and $K_{\mathrm{IC}}^{\mathrm{un}}$ can be expressed as

$$
K_{\mathrm{IC}}^{\mathrm{un}}=K_{\mathrm{IC}}^{\mathrm{ini}}+K_{\mathrm{IC}}^{\mathrm{\sigma}}
$$

363 Here, $K_{\mathrm{IC}}^{\sigma}$ is the SIF caused by the cohesive stress at the critical cracking state and could be calculated using Eq. (11), with its evolution from the crack initiation to unstable propagation illustrated in Fig. 8 


$$
K_{\mathrm{IC}}^{\sigma}=-\int_{a_{0} / a_{\mathrm{c}}}^{1} 2 \sqrt{\frac{a_{\mathrm{c}}}{\pi}} \sigma(U) F(U, V) \mathrm{d} U
$$

366 where $V=\frac{a_{\mathrm{c}}}{D}, U=\frac{x}{a_{\mathrm{c}}}, x$ is the range of the crack length, and the function $F(U, V)$ is given as

$$
F(U, V)=\frac{3.52(1-U)}{(1-V)^{3 / 2}}-\frac{4.35-5.28 U}{(1-V)^{1 / 2}}+\left[\frac{1.30-0.30 U^{3 / 2}}{\left(1-U^{2}\right)^{1 / 2}}+0.83-1.76 U\right][1-(1-U) V]
$$

It can be seen that $K_{\mathrm{IC}}^{\mathrm{\sigma}}$ is governed by $C M O D_{\mathrm{c}}$ and $a_{\mathrm{c}}$. According to the tested results in the experiment, the values of $C M O D_{\mathrm{c}}$ and $a_{\mathrm{c}}$ under the static loading were very close to those under the sustained loading (see Table 2). The calculated values of $K_{\mathrm{IC}}^{\circ}$ using Eq. (11) are listed in Table 2,

371 which indicate that the values of $K_{\mathrm{IC}}^{\circ}$ were little affected by sustained loading. In addition, based on the

372 aforementioned study, the initial fracture toughness is also a material parameter without the effect of 373 sustained loading. According to Eq. (10), therefore, the unstable fracture toughness also cannot be

374 affected by the long-term loading although the peak loads were different under varied sustained 375 loading levels.

\section{Conclusions}

The creep tests under three load levels, i.e. $30 \% P_{\max }, 60 \% P_{\max }$ and the crack initiation load, were conducted on the TPB specimens for 30 days. After that, the specimens were removed from the frames and immediately loaded up to failure under the static TPB loading. Based on the experimental results, the effects of sustained loading on the fracture properties, including the initial cracking load $P_{\text {ini, }}$, the peak load $P_{\max }$, the fracture energy $G_{\mathrm{f}}$, the critical crack propagation length $\Delta a_{\mathrm{c}}$, the initial cracking toughness $K_{\mathrm{IC}}^{\mathrm{ini}}$, and the unstable fracture toughness $K_{\mathrm{IC}}^{\mathrm{un}}$, were discussed. By introducing Norton's model to take into account the influence of the stress relaxation in the creep tests, the evolution of the

SIFs was numerically investigated by combining with the $J$-integral method. Based on the experimental and numerical results, the following conclusions can be drawn: 
had almost no effects on the tested values of $G_{\mathrm{f}}$ and $\Delta a_{\mathrm{c}}$ for the specimens after the long-term loading.

388 The increases in $P_{\mathrm{ini}}$ and $P_{\max }$ were observed for the creep specimens, resulting in the increases in $K_{\mathrm{IC}}^{\mathrm{ini}}$ 389 and $K_{\mathrm{IC}}^{\mathrm{un}}$ based on the LEFM theory.

2. In the creep tests, the SIFs decreased over time due to the stress relaxation in concrete, and their magnitudes were associated with the sustained loading levels. Meanwhile, the stress relaxation led to the increases in $P_{\text {ini }}$ and $P_{\max }$ because the increments were used to fill the relaxed stress during the creep process. However, compared with the aging specimens, $K_{\mathrm{IC}}^{\mathrm{ini}}$ and $K_{\mathrm{IC}}^{\mathrm{un}}$ of the creep specimens were not affected by the sustained loading if the stress relaxations were considered.

3. Due to the effects of the stress relaxation, the calculated values of $K_{\mathrm{IC}}^{\mathrm{ini}}$ and $K_{\mathrm{IC}}^{\mathrm{un}}$ based on the

LEFM method in the case of sustained loading would be over-estimated due to the increased $P_{\text {ini }}$ and

$P_{\max }$. However, their real values were almost the same as those from the static TPB tests. In practice, therefore, $K_{\mathrm{IC}}^{\mathrm{ini}}$ and $K_{\mathrm{IC}}^{\text {un }}$ derived from the static TPB tests can still be used to assess the cracking-resistance of concrete and the stability of concrete structures under different load levels.

\section{Acknowledgments}

402 The authors gratefully acknowledge the financial support of the National Natural Science Foundation 403 of China under the grants of NSFC 51878011, NSFC 51421064 and NSFC 51478083, the 404 Fundamental Research Funds for the Central Universities of China under the grants of DUT17LK06, 405 and the National Basic Research Program of China (The 973 Program) under the grant of $2015 \mathrm{CB} 057703$.

\section{References}

Barpi, F., Ferrara, G., Imperato, L., and Valente, S. (1999). "Lifetime of concrete dam models under constant loads." Mater. Struct, 32(2): 103-111.

Bažant, Z. P., and Gettu, R. (1992). "Rate effects and load relaxation in static fracture of concrete." Aci. Mater. J., 89(5): 456-468.

Bažant, Z. P., and Li, Y. N. (1996). "Cohesive crack model with rate-dependence and viscoelasticity." Proc. Eng. Mech., 852-856. 
Bažant, Z. P., and Xian, Y. Y. (1997). “Crack growth and lifetime of concrete under long time loading.” J. Eng. Mech., 123(4): 350-358.

Beushausen, H., Masuku, C., and Moyo, P. (2012). "Relaxation characteristics of cement mortar subjected to tensile strain.” Mater. Struct., 45(8): 1181-1188.

Dong, W., Wu, Z., and Zhou, X. (2013a). "Calculating crack extension resistance of concrete based on a new crack propagation criterion." Constr. Build. Mater., 38(2): 879-889.

Dong, W., Zhou, X., and Wu, Z. (2013b). “On fracture process zone and crack extension resistance of concrete based on initial fracture toughness." Constr. Build. Mater., 49(6): 352-363。

Dong, W., Rong, H., Wu, Q., and Li, J. (2018a). "Investigations on the FPZ evolution of concrete after sustained loading by means of the DIC technique." Constr. Build. Mater., 18: 49-57.

Dong, W., Zhang, X., Zhang, B., and Wu, Q. (2018b). "Influence of sustained loading on fracture properties of concrete." Eng. Fract. Mech., 200: 134-145.

Hamed, E. (2016). "Relaxation behavior of concrete under sustained uniaxial compressive deformation." J. Mater. Civ. Eng., 10.1061/(ASCE)MT.1943-5533, 0001539.

Kraus, H. (1980). Creep Analysis. John Wiley \& Sons Inc, New York, USA.

Kumar, S., and Barai, S. V. (2008). "Influence of specimen geometry on determination of double-K fracture parameters of concrete: a comparative study." Int. J. Fract., 149(1): 47-66.

Kumar, S., and Barai, S. V. (2009). "Determining double-K fracture parameters of concrete for compact tension and wedge splitting tests using weight function." Eng. Fract. Mech., 76(7): 935-948.

Li, Y. N., and Bazant, Z. P. (1997). "Cohesive crack model with rate-dependent opening and viscoelasticity: II. Numerical algorithm, behavior and size effect." Int. J. Fract., 86(3): 267-288.

Mazzotti, C., and Savoia, M. (2003). "Nonlinear creep damage model for concrete under uniaxial compression.” $J$. Eng. Mech., 129(9): 1065-1075.

Naoki, T., Kariya, Y., and Kanda, Y. (2011). "Fatigue life and fracture behavior of micro size Sn-Ag-Cu solder joint." Proc., ASME 2011 Pacific Rim Technical Conference and Exhibition on Packaging and Integration of Electronic and Photonic Systems, Oregon, USA.

National Standard of the People's Republic of China (NSPRC) (2003) GB/T 50081-2002 Standard for Test Method of Mechanical Properties on Ordinary Concrete, Ministry of Construction of the People's Republic of China, China.

Omar, M., Loukili, A., Pijaudier-Cabot, G., and Le Pape, Y. (2009). “Creep-damage coupled effects: Experimental investigation on bending beams with various sizes." J. Mater. Civ. Eng., 21(2): 65-72.

Oza, A., Vanderby, R., and Lakes, R. S. (2003). "Interrelation of creep and relaxation for nonlinearly viscoelastic materials: application to ligament and metal." Rheol. Acta, 42(6): 557-568.

RILEM (1990). "Determination of fracture parameters $\left(K_{\mathrm{Ic}}^{\mathrm{s}}\right.$ and $\left.\mathrm{CTOD}_{\mathrm{c}}\right)$ of plain concrete using three-point bend tests. TC 89-FMT fracture mechanics of concrete-test methods. ” Mater. Struct., 23(6): 457-460.

Rong, H., Dong, W., Zhang, X., and Zhang, B. (2019). "Size effect on fracture properties of concrete after sustained loading." Mater Struct, 52(1): 1-12.

Saliba, J., Loukili, A., and Grondin, F. (2010) "Coupling creep and damage in concrete under high sustained loading." Proc., 7th Int. Conference on Fracture Mechnics of Concrete and Concrete Structures, Seoul, Korea.

Saliba, J., Loukili, A., Grondin, F., and Regoin, J. P. (2012). "Experimental study of creep-damage coupling in concrete by acoustic emission technique.” Mater. Struct., 45(9): 1389-1401.

Saliba, J., Loukili, A., Grondin, F., and Regoin, J. P. (2014). "Identification of damage mechanisms in concrete 
under high level creep by the acoustic emission technique." Mater. Struct., 47(6): 1041-1053.

Tada, H., Paris, P., and Irwin, G. (1985). The Stress Analysis of Cracks Handbook. 2nd Ed., Paris Productions, Hellerton PA.

Valente, S., and Barpi, F. (2011). "Failure lifetime of concrete structures under creep and fracture." Mag. Concr.

Xu, S. L., and Reinhardt, H. W. (1999a). "Determination of double-K criterion for crack propagation in quasi-brittle fracture, Part I: Experimental investigation of crack propagation.” Int. J. Fract., 98(2): 111-149.

463

464

465

466

467

468

469

470

471

472

473

474

475

476

477

478

479

480

481

482

483

484

485

486

487

488

489

490

491

492

493

494

495

496

497

Xu, S. L., and Reinhardt, H. W. (1999b). "Determination of double-K criterion for crack propagation in quasi-brittle fracture, Part II: Analytical evaluating and practical measuring methods for three-point bending notched beams." Int. J. Fract., 98(2): 151-177.

Xu, S. L., and Reinhardt, H. W. (1999c). "Determination of double-K criterion for crack propagation in quasi-brittle fracture, Part III: Compact tension specimens and wedge splitting specimens." Int. J. Fract., 98(2): 179-193.

$\mathrm{Xu}, \mathrm{S}$., and Zhu, Y. (2009). "Experimental determination of fracture parameters for crack propagation in hardening cement paste and mortar." Int. J. Fract., 157(1): 33-43.

Yuan, J., Xu, H., and Ni, Y. Z. (2013). "Research on a New Secondary Creep Model and Creep Damage Evolution for P92 Steel." Adv. Mater. Res., 690-69: 157-163.

Zhang, J., Leung, C. K. Y., and Xu, S. L. (2010). "Evaluation of fracture parameters of concrete from bending test using inverse analysis approach.” Mater. Struct., 43(6): 857-874.

Zhang, X., and Xu, S. (2011). "A comparative study on five approaches to evaluate double-K fracture toughness parameters of concrete and size effect analysis." Eng. Fract. Mech., 78(10): 2115-2138.

Zhou, F. P. (1992). "Time-dependent crack growth and fracture in concrete." Technical Rep. Tvbm-1011, Div. of Building Materials, Lund Univ., Lund, Sweden. 
Table 1. Material properties of concrete at 28 days

\begin{tabular}{cccc}
\hline Material property & $\begin{array}{c}E \\
(\mathrm{GPa})\end{array}$ & $\begin{array}{c}f_{\mathrm{t}} \\
(\mathrm{MPa})\end{array}$ & $\begin{array}{c}f_{\mathrm{c}} \\
(\mathrm{MPa})\end{array}$ \\
\hline Quantity & 33.5 & 3.07 & 39.10 \\
\hline
\end{tabular}

499

500

Table 2. Experimental and numerical results of the TPB specimens

\begin{tabular}{|c|c|c|c|c|c|c|c|c|c|c|c|}
\hline \multirow[t]{2}{*}{ Specimens } & \multirow{2}{*}{$\begin{array}{c}P_{\text {ini }} \\
(\mathrm{kN})\end{array}$} & \multirow{2}{*}{$\begin{array}{l}P_{\max } \\
(\mathrm{kN})\end{array}$} & \multirow{2}{*}{$\begin{array}{c}G_{\mathrm{f}} \\
(\mathrm{N} / \mathrm{m})\end{array}$} & \multirow{2}{*}{$\begin{array}{c}K_{\mathrm{IC}}^{\mathrm{\sigma}} \\
\left(\mathrm{MPa} \cdot \mathrm{m}^{1 / 2}\right)\end{array}$} & \multicolumn{2}{|c|}{$\begin{array}{c}K_{\mathrm{IC}}^{\mathrm{ini}} \\
\left(\mathrm{MPa} \cdot \mathrm{m}^{1 / 2}\right)\end{array}$} & \multicolumn{2}{|c|}{$\begin{array}{c}K_{\mathrm{IC}}^{\mathrm{un}} \\
\left(\mathrm{MPa} \cdot \mathrm{m}^{1 / 2}\right)\end{array}$} & \multirow{2}{*}{$\begin{array}{l}C M O D_{\mathrm{c}} \\
\text { (um) }\end{array}$} & \multicolumn{2}{|c|}{$\begin{array}{c}a_{\mathrm{c}} \\
(\mathrm{mm})\end{array}$} \\
\hline & & & & & Eq.(6) & Num. & $\mathrm{Eq}(6)$ & Num. & & Eq.(8) & Exp. \\
\hline C-aging-1 & 2.72 & 3.92 & 102.6 & 0.96 & 0.52 & 0.49 & 1.29 & 1.45 & 38.31 & 49.4 & 49.9 \\
\hline $\mathrm{C}$-aging-2 & 2.70 & 4.22 & 94.1 & 0.93 & 0.52 & 0.48 & 1.37 & 1.41 & 38.27 & 48.8 & 50.6 \\
\hline $\mathrm{C}$-aging-3 & 2.84 & 4.08 & 104.3 & 0.87 & 0.54 & 0.51 & 1.27 & 1.38 & 36.18 & 47.4 & 48.2 \\
\hline Mean value & 2.75 & 4.07 & 100.3 & 0.92 & 0.52 & 0.50 & 1.29 & 1.42 & 37.59 & 48.5 & 49.6 \\
\hline C-30-1 & 3.27 & 4.75 & 95.0 & 0.87 & 0.63 & 0.53 & 1.48 & 1.40 & 38.31 & 47.4 & 52.8 \\
\hline C-30-2 & 3.23 & 4.47 & 95.3 & 0.79 & 0.62 & 0.52 & 1.31 & 1.31 & 31.68 & 45.6 & 46.9 \\
\hline C-30-3 & 3.33 & 4.31 & 106.5 & 1.06 & 0.64 & 0.54 & 1.52 & 1.60 & 36.18 & 51.4 & 52.5 \\
\hline Mean value & 3.28 & 4.51 & 98.9 & 0.90 & 0.63 & 0.53 & 1.44 & 1.43 & 35.39 & 48.2 & 50.7 \\
\hline C-60-1 & 3.42 & 4.70 & 100.4 & 0.84 & 0.71 & 0.53 & 1.43 & 1.37 & 32.11 & 46.8 & 48.8 \\
\hline C-60-2 & 3.40 & 4.54 & 106.7 & 1.02 & 0.67 & 0.54 & 1.55 & 1.56 & 36.18 & 50.6 & 51.2 \\
\hline C- $60-3$ & 3.36 & 4.68 & 96.9 & 0.91 & 0.68 & 0.53 & 1.49 & 1.44 & 36.18 & 48.2 & 50.6 \\
\hline Mean value & 3.39 & 4.64 & 101.3 & 0.92 & 0.68 & 0.54 & 1.49 & 1.46 & 34.82 & 48.5 & 50.2 \\
\hline C-ini-1 & 3.40 & 4.61 & 106.7 & 0.88 & 0.69 & 0.54 & 1.44 & 1.42 & 32.72 & 47.6 & 52.9 \\
\hline C-ini-2 & 3.33 & 4.51 & 95.4 & 0.92 & 0.68 & 0.53 & 1.45 & 1.45 & 38.31 & 48.6 & 54.5 \\
\hline C-ini-3 & 3.49 & 5.10 & 102.8 & 0.97 & 0.71 & 0.55 & 1.69 & 1.52 & 36.18 & 49.6 & 48.5 \\
\hline Mean value & 3.40 & 4.74 & 101.6 & 0.93 & 0.69 & 0.54 & 1.53 & 1.47 & 35.73 & 48.6 & 52.0 \\
\hline
\end{tabular}

501

502

503

504

505

506

507

508

509

510

511

512

513

514

515

516

517

518

519

520 


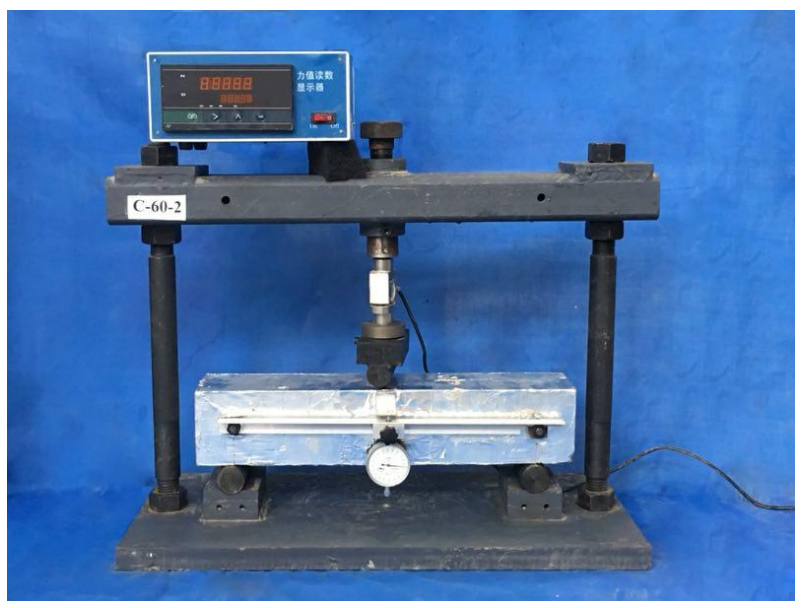

Fig. 1. Set-up of the creep test

523

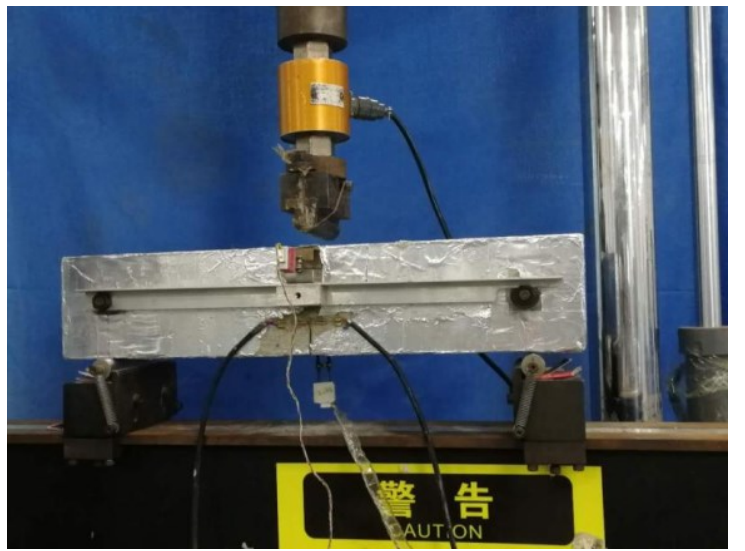

(a) Measuring loading point displacement and $C M O D$

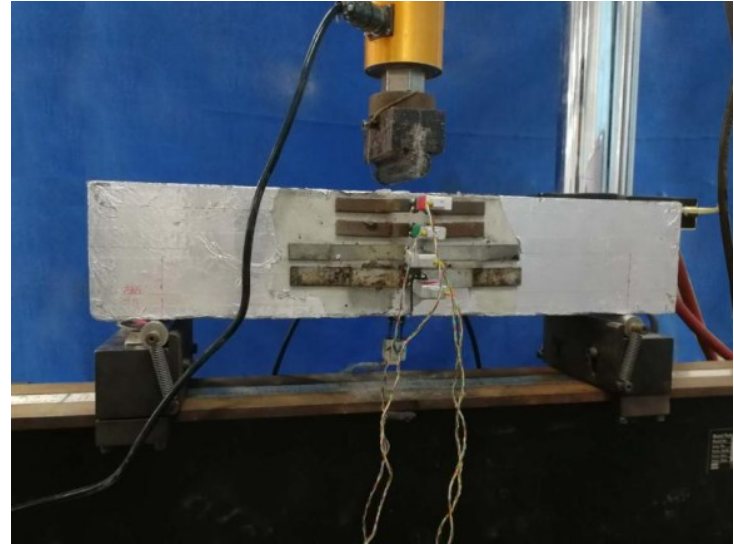

(b) Measuring crack opening displacements

Fig. 2. Experimental set-ups for the TPB tests after sustained loading
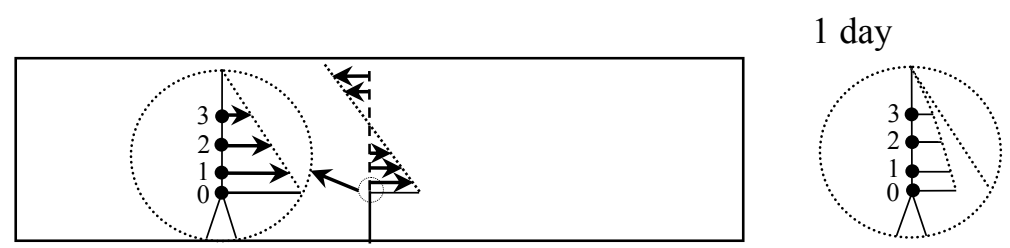

2 days

Fig. 3. Stress variations in front of the pre-crack tip over time 
532

533

534

535

536

537

538

539

540

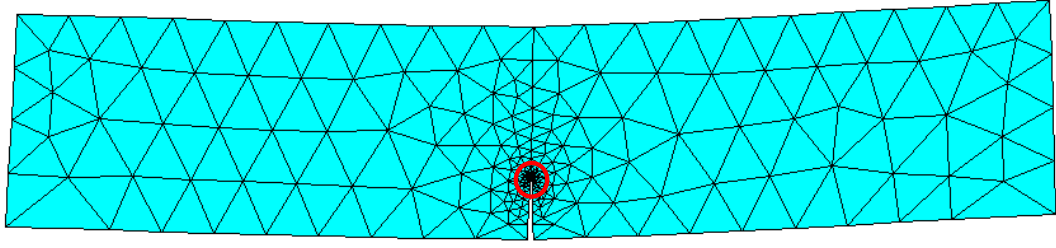

Fig. 4. Element mesh of the beam model

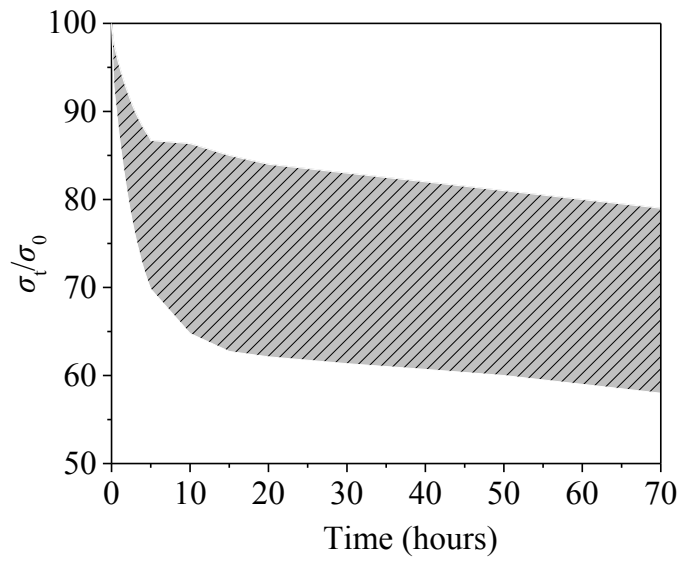

(a) Relative stress over time

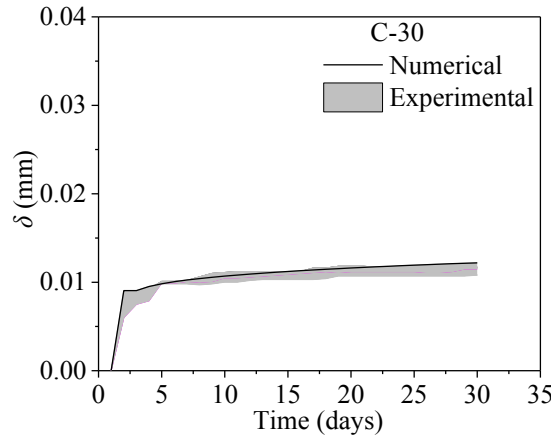

(b) C-30 series

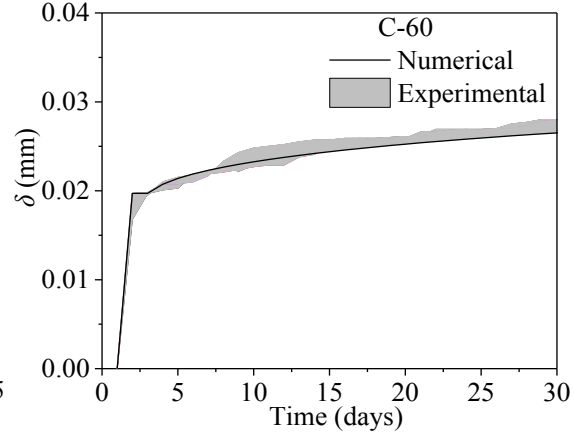

(c) $\mathrm{C}-60$ series

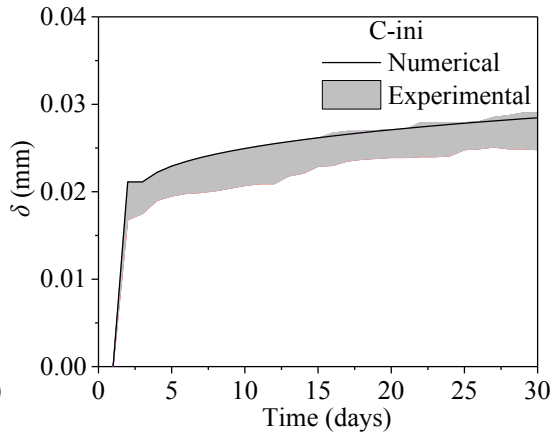

(d) C-ini series

Fig. 5. Relative stress and loading point deformation versus time 


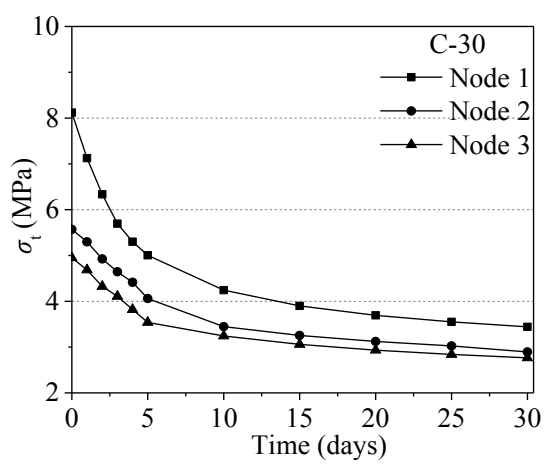

(a) $\mathrm{C}-30$ series

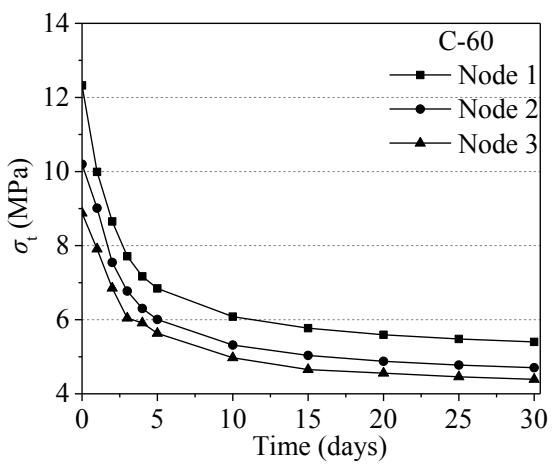

(b) C-60 series

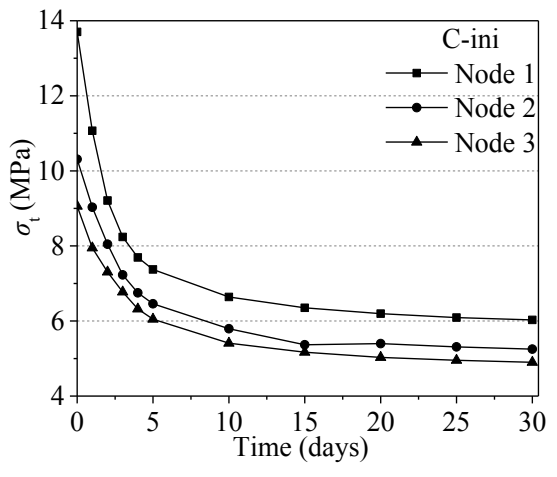

(c) C-ini series

Fig. 6. Evolution of stresses over time for creep specimens obtained from the numerical analyses

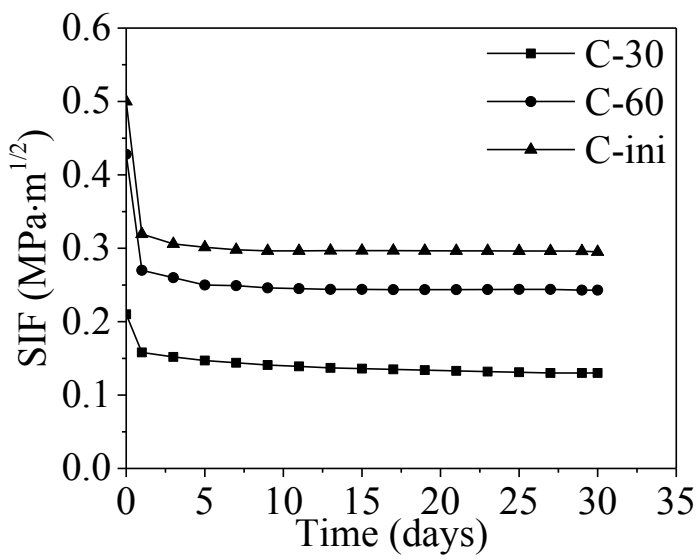

Fig. 7. Variations of the SIFs in the creep tests obtained from the numerical analyses

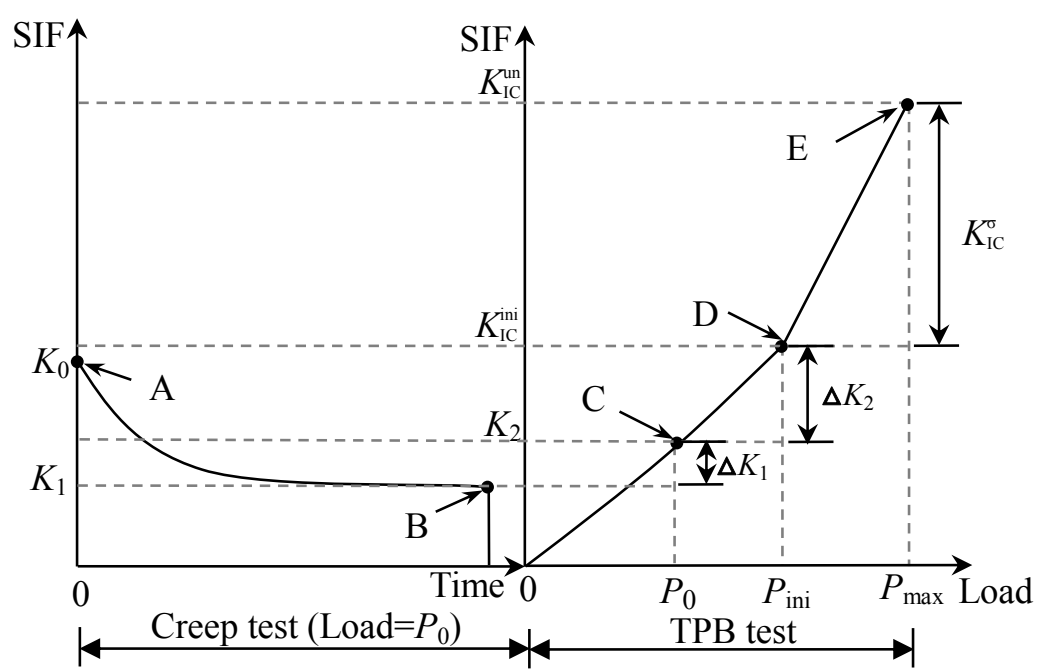

Fig. 8. Evolutions of SIFs in the creep tests and TPB tests 


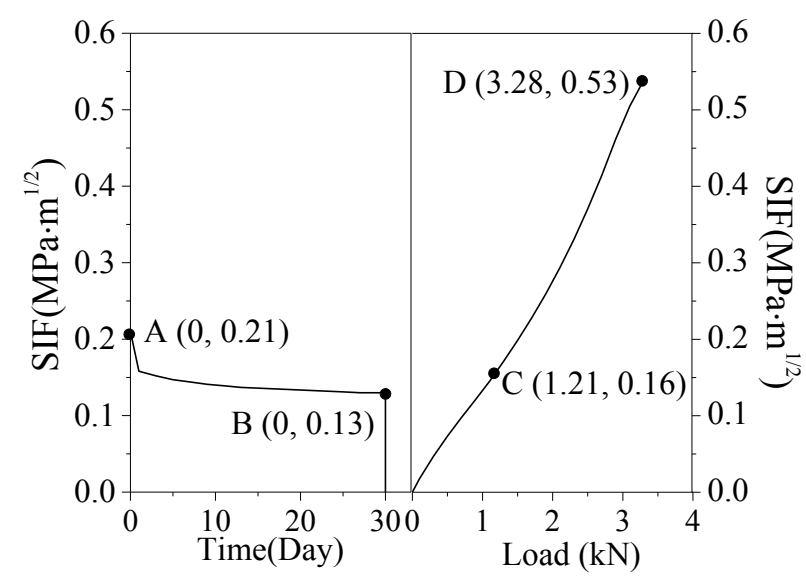

(a) C-30 series

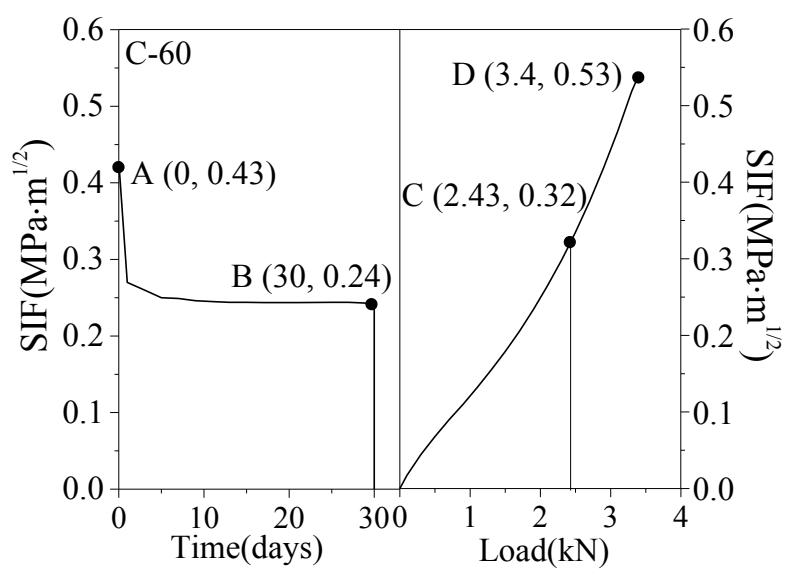

(b) $\mathrm{C}-60$ series

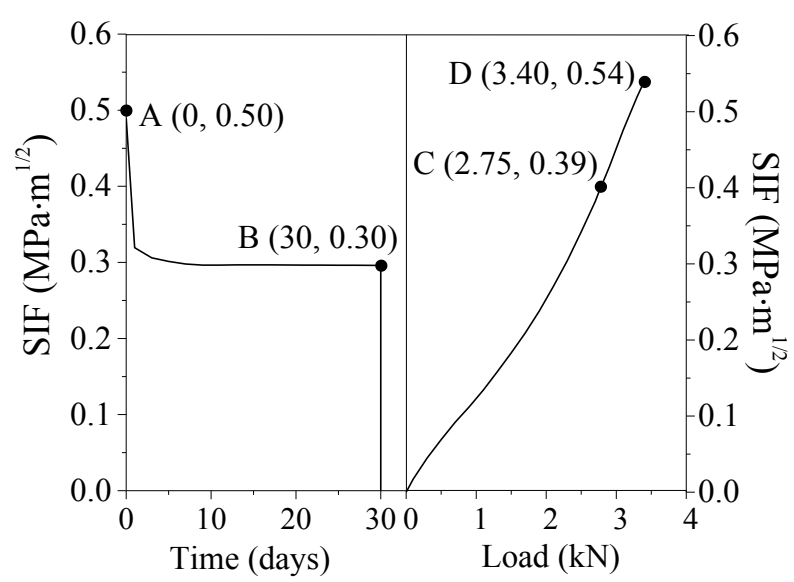

(c) C-ini series

Fig. 9. Evolutions of the SIFs for different series specimens obtained from the numerical analyses 


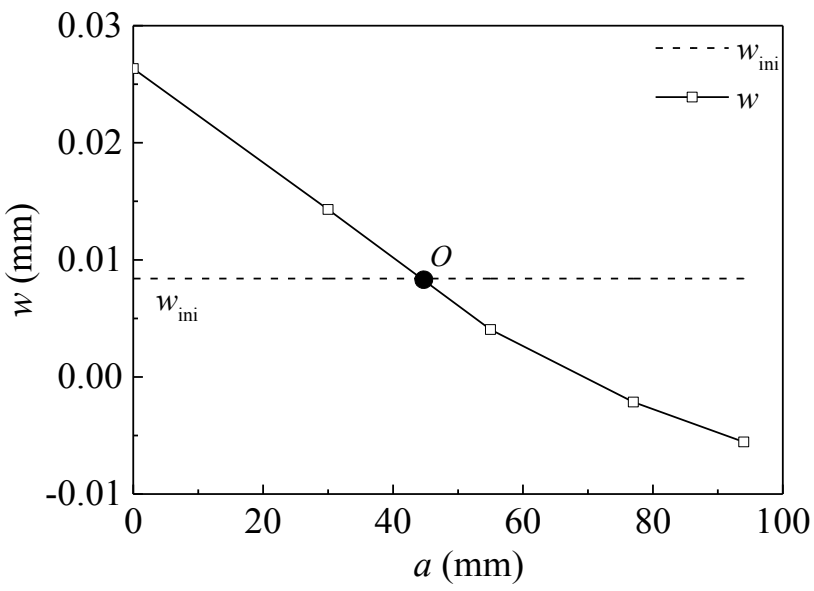

Fig. 10. Determination of the crack tip position based on the experimental results 